\title{
Intra-annual link of spring and autumn precipitation over France
}

\section{Journal Article}

Author(s):

Hirschi, Martin (D); Seneviratne, Sonia I. (D)

Publication date:

2010-12

Permanent link:

https://doi.org/10.3929/ethz-b-000158407

Rights / license:

In Copyright - Non-Commercial Use Permitted

Originally published in:

Climate Dynamics 35(7-8), https://doi.org/10.1007/s00382-009-0734-1 


\title{
Intra-annual link of spring and autumn precipitation over France
}

\author{
Martin Hirschi · Sonia I. Seneviratne
}

Received: 6 March 2009/Accepted: 22 December 2009/Published online: 14 January 2010

(C) Springer-Verlag 2010

\begin{abstract}
In a previous study, an intra-annual relationship of observed precipitation, manifested by negative correlations between domain-averaged spring and autumn precipitation of the same year, was found in two domains covering France and Central Europe for the period 19721990 (Hirschi et al., J Geophys Res 112(D22109), 2007). Here, this link and its temporal evolution over France during the twentieth century is further investigated and related to the atmospheric circulation and North Atlantic/ Mediterranean sea surface temperature (SST) patterns. Observational datasets of precipitation, mean sea level pressure (MSLP), atmospheric teleconnection patterns, and SST, as well as various global and regional climate model simulations are analyzed. The investigation of observed precipitation by means of a running correlation with a 30-year time window for the period 1901-present reveals a decreasing trend in the spring-to-autumn correlations, which become significantly negative in the second half of the twentieth century. These negative correlations are connected with similar spring-to-autumn correlations in observed MSLP, and with negatively correlated spring East Atlantic (EA) and autumn Scandinavian (SCA) teleconnection pattern indices. Maximum covariance analyses of SST with these atmospheric variables indicate that at least part of the identified spring-to-autumn link is mediated through SST, as spring precipitation and MSLP are connected with the same autumn SST pattern as are autumn precipitation, MSLP and the SCA pattern index. Except for
\end{abstract}

\footnotetext{
M. Hirschi $(\bowtie) \cdot$ S. I. Seneviratne

Institute for Atmospheric and Climate Science, ETH Zurich,

Universitaetsstrasse 16, 8092 Zurich, Switzerland

e-mail: m.hirschi@alumni.ethz.ch

S. I. Seneviratne

e-mail: sonia.seneviratne@env.ethz.ch
}

ERA-40 driven regional climate models from the EU-FP6 project ENSEMBLES, the analyzed regional and global climate models, including Intergovernmental Panel on Climate Change (IPCC) Fourth Assessment Report (AR4) simulations, do not capture this observed variability in precipitation. This is associated with the failure of most models in simulating the observed correlations between spring and autumn MSLP. While the causes for the identified relationship cannot be fully established its timing suggests a possible link with increased aerosol loading in the global dimming period.

Keywords Precipitation variability - France . Observations $\cdot$ Regional/global climate models

\section{Introduction}

Memory effects in the climate system are of key relevance for climate prediction and seasonal forecasting. Elements of the climate system that induce low-frequency variability are for instance sea surface temperatures, soil moisture content, and snow cover (e.g., Koster et al. 2000; Sutton and Hodson 2003; Seneviratne et al. 2006a; Schubert et al. 2008). Here we investigate a spring-to-autumn lag-correlation feature identified in a previous study for precipitation over France (Hirschi et al. 2007). We analyze the temporal evolution of this correlation feature and the possible causes underlying it.

In Europe, climate variability is determined by several factors. In winter, it is strongly influenced by the North Atlantic Oscillation (NAO), which represents the most important teleconnection pattern in the North AtlanticEuropean area (e.g., Wanner et al. 2001; Trigo et al. 2002; Hurrell et al. 2003). The NAO is associated with changes in the position and strength of the surface 
westerly winds across the Atlantic onto Europe. This has implications for the input of heat and moisture to the continent, and there modifies surface air temperature and precipitation (e.g., Hurrell 1995; Hurrell and van Loon 1997). The influence of the NAO on European climate is weaker in non-winter seasons (e.g., Wanner et al. 2001; Hurrell et al. 2003). In spring and summer, climate variability over land in transitional climate regimes (in the Mediterranean region, and in some summers also in Central Europe, e.g., Seneviratne et al. 2006b; Fischer et al. 2007) is also dependent on land surface processes and the interaction of the land surface with the atmosphere (e.g., Koster et al. 2000, 2004; Seneviratne et al. 2006b, 2009). However, coherent fluctuations of surface pressure, temperature and precipitation occur throughout the year (e.g., Hurrell et al. 2003).

Besides the NAO, other atmospheric teleconnection patterns have been identified as determinant for the European climate, including the East Atlantic (EA) and the Scandinavian (SCA) patterns (Barnston and Livezey 1987) which we refer to in this paper. The EA pattern is structurally similar to the NAO, and consists of a north-south dipole of anomaly centers spanning the North Atlantic from east to west. The anomaly centers of the EA pattern are displaced southeastward to the approximate nodal lines of the NAO pattern. The SCA pattern consists of a primary circulation center over Scandinavia, with weaker centers of opposite sign over western Europe and eastern Russia/ western Mongolia. The SCA pattern has been previously referred to as the Eurasia-1 pattern by Barnston and Livezey (1987).

Regarding the variability and changes of precipitation in Europe, the influence of atmospheric circulation and teleconnection patterns has been analyzed so far in a number of papers for winter (e.g., Zorita et al. 1992; Hurrell 1995; Hurrell and van Loon 1997; Wibig 1999), as well as for other seasons (e.g., Zveryaev 2004; Pauling et al. 2006; Casty et al. 2007). The influence of the NAO on precipitation in Europe was found to be non-stationary over time (e.g., Pauling et al. 2006; Zveryaev 2006; Massei et al. 2007; Zveryaev 2008; Vicente-Serrano and López-Moreno 2008). Hypotheses to explain this nonstationarity have been proposed and include the modification of the meridional pressure gradient (Zveryaev 2006) and inter-decadal shifts in the location of the position of the NAO pressure centers (Vicente-Serrano and López-Moreno 2008). Moreover, the link between regional precipitation and the atmospheric circulation exhibits essential seasonality (Zveryaev 2006). Zveryaev (2008) found that during climatic periods of weak links to the NAO (both in spring and autumn), precipitation variability over Europe was driven by the SCA teleconnection pattern.
The above studies focused on the changing influence of the atmospheric circulation on precipitation in different seasons. However, the implications of this changing seasonal relationship on intra-annual lag correlations of seasonal precipitation remains open. In Hirschi et al. (2007), negative correlations between spring and autumn precipitation of the same year were found in two domains covering France and Central Europe for the time period 1972-1990. Here we further investigate this link and its temporal evolution over France during the twentieth century and relate it to the atmospheric circulation and North Atlantic/Mediterranean sea surface temperature (SST) patterns. The link is analyzed using observational datasets of precipitation, mean sea level pressure (MSLP), atmospheric teleconnection patterns and SST. Moreover, we analyze various global and regional climate models in terms of this phenomenon.

The paper is structured as follows. After the presentation of the observed link between spring and autumn precipitation (Sect. 2.1), its representation is analyzed in various climate models (Sect. 2.2). In Sect. 3, possible causes for the observed link are investigated, and potential explanations for the failure of the models in its representation are discussed. Finally, concluding remarks are provided in Sect. 4.

\section{Phenomenon description}

\subsection{Observational evidence}

A peculiar link between observed spring and autumn precipitation of the same year was found in two domains covering France and Central Europe for the period 19721990 in a recent study by Hirschi et al. (2007). This link consists in negative correlations between domain-averaged precipitation of these two seasons. ${ }^{1}$ To further analyze this phenomenon and its temporal persistence over France, the temporal evolution of this spring-to-autumn link over the twentieth century is analyzed here using observed precipitation from the Climate Research Unit (CRU, available 1901-2002, Mitchell and Jones 2005), from the Global Precipitation Climatology Center (GPCC, available 1901-2007, Rudolf et al. 1994), the E-Obs dataset from the EU-FP6 project ENSEMBLES (available 1950-2006, Haylock et al. 2008), and station data from the European Climate Assessment \& Dataset project (ECA\&D, Klein Tank et al. 2002). In the case of ECA\&D, only stations which are considered to be useful according to four homogeneity tests (see Wijngaard et al. 2003), and which

\footnotetext{
${ }^{1}$ Note that there does not exist any significant correlation between autumn and next-year spring precipitation.
} 
have data available for the full 1950-2008 period (i.e., without missing values) are incorporated in the analysis (which results in 11 stations fulfilling these criteria). Moreover, precipitation from the European Centre for Medium-Range Weather Forecasts (ECMWF, ERA-40) and the National Centers for Environmental Prediction/ National Center for Atmospheric Research (NCEP/NCAR) reanalyses are included in the analysis (available for 19582001 and 1948-2008, respectively).

These monthly precipitation datasets are averaged over France and the spring (MAM) and autumn (SON) values are calculated for each year. Note that the same domain definition as in Hirschi et al. (2007) is used here, which corresponds to the four largest catchments of France upstream their lowest runoff stations (i.e., the Rhone, Seine, Loire, Garonne catchments, see also Fig. 5). The temporal evolution of the described spring-to-autumn link in precipitation is then derived by applying a running correlation with a 30-year time window on the de-trended time series of spring and autumn precipitation. Note that there is no significant autocorrelation apparent in the respective time series of spring and autumn precipitation. The resulting temporal evolution of the correlations between spring and autumn precipitation (Fig. 1, center year denotes year 16 of the 30-year time window) reveals positive correlations at the beginning of the twentieth century, then a downward trend in the observed correlations, and correlations becoming significantly negative on the 5\% significance level (two-tailed test, black dashed lines in Fig. 1) from the mid-1950s on. There is also some indication of a possible reversal of the trend towards the end of the century. The four observational datasets closely agree on this temporal evolution of the spring-to-autumn correlations. Note in particular that this is also the case for the homogeneity-tested ECA\&D stations, thus giving confidence that the observed signal in the gridded datasets is not an artifact due to changes in the observational networks or station density. The two reanalysis datasets show a delay of about 10 years in the onset of the significantly negative correlations, and the negative signal in the NCEP/ NCAR reanalysis is not as persistent as in the other datasets. Here we display the Pearson's correlation, however, similar results are obtained when using the more robust Spearman's rank correlation instead (not shown).

To investigate the temporal robustness of the negative correlations, various non-parametric tests have been applied. The theoretical 5\% significance level (two-tailed test) has been validated by resampling the respective 30 years around the center year. The 95\% confidence interval from this resampling test (light grey shading) agrees well with the theoretical threshold for all datasets. Furthermore, to test the randomness of the significantly negative correlations, a pair-wise resampling of 30 years from the whole time series was applied in the case of CRU and GPCC. The resulting 95\% confidence interval is denoted in the CRU and GPCC panels by the horizontal grey lines and reveals that the probability for the observed negative correlations to be random is less than $2.5 \%$.

To examine the stationary behavior of the correlations, the minimal correlations have been estimated from a parametric bootstrap for CRU and GPCC (assuming a correlation of zero over the whole period). After generating random time series from the spring and autumn distributions of precipitation of the entire periods (both approximately normally distributed), the minima from the running correlations applied to these artificial time series has been derived. The median and the $95 \%$ confidence intervals of these minimum correlations are displayed by the bars on the left in the respective panels. The observed negative correlations lie mostly below the minimum bar both for CRU and GPCC, indicating that the observed negative spring-to-autumn link is connected with a non-stationarity in the climate system.

Lastly, as a measure of uncertainty of the correlations, a Jackknife estimate of its standard error has been derived for every center year (dark grey shading). All these tests support the significance and non-randomness of the observed negative correlations between spring and autumn precipitation in the second half of the twentieth century. Moreover, the spatial robustness of the correlations is also indicated since the extension of the domain over which the precipitation data is averaged to whole Central Europe (same domain as in Hirschi et al. 2007) reveals the same temporal evolution of the correlations including the (slightly less pronounced) significantly negative correlations in the second half of the twentieth century (see also Hirschi et al. 2007).

\subsection{Analysis of climate models}

Ideally, such a climate feature should also be identifiable in climate simulations of the same period (if induced by a specific forcing included in the climate simulations). To verify this, we investigate Intergovernmental Panel on Climate Change (IPCC) Fourth Assessment Report (AR4) simulations from free-running coupled general circulation models (GCMs) from the World Climate Research Programme's (WCRP's) Coupled Model Intercomparison Project phase 3 (CMIP3) multi-model dataset. Three AR4 GCMs (i.e., ECHAM5, GFDL CM2.1, HadGEM1) that have been shown to have accurate representation of present-day North-hemispheric circulation patterns (van Ulden and van Oldenborgh 2006) are analyzed over the whole last century, the others for the period 1960-1989, when the observed negative spring-to-autumn precipitation correlations occur. Moreover, AMIP-style (Atmospheric Model 
French domain: running precip(MAM), precip(SON) correlation (30 years)

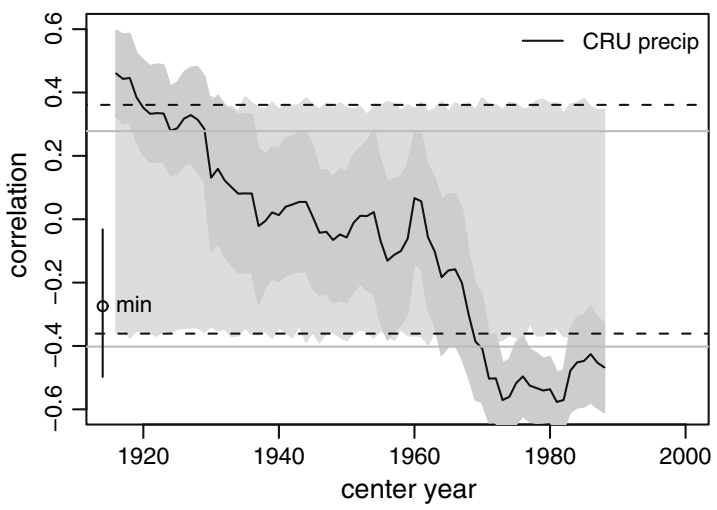

French domain: running precip(MAM), precip(SON) correlation (30 years)

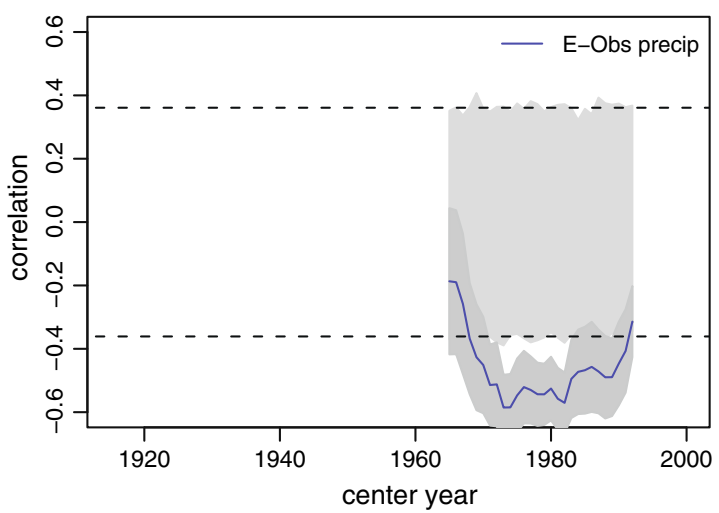

French domain: running precip(MAM), precip(SON) correlation (30 years)

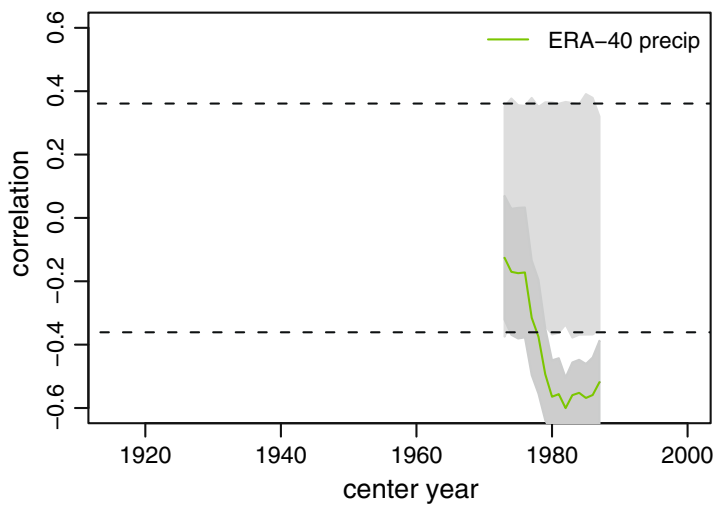

Fig. 1 Temporal evolution of the 30-year spring-to-autumn precipitation correlation in France (domain: see Fig. 5) for the different observational datasets and the ERA-40 and NCEP/NCAR reanalyses. The theoretical 5\% significance level (two-tailed test) is displayed as black dashed lines, the $95 \%$ confidence interval from the resampling test as light grey shading, and the Jackknife uncertainty of the correlation estimate as dark grey shading. In the case of CRU and

Intercomparison Project) GCM simulations from the EU-project PRUDENCE (Prediction of Regional Scenarios and Uncertainties for Defining European Climate Change
French domain: running precip(MAM), precip(SON) correlation (30 years)

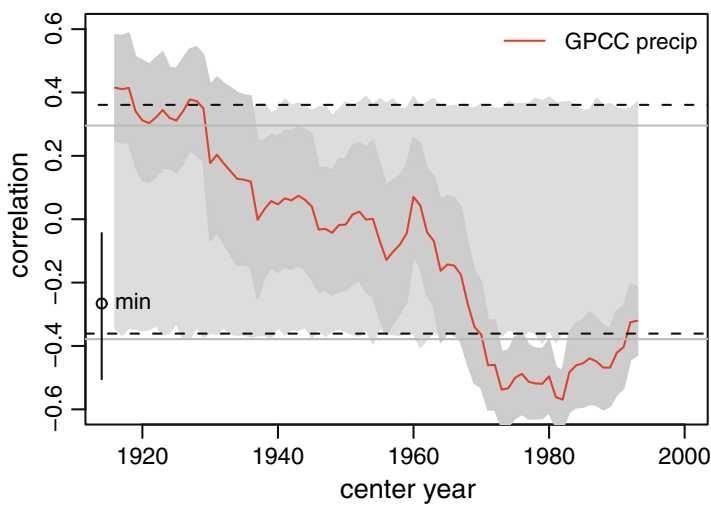

French domain: running precip(MAM), precip(SON) correlation (30 years)

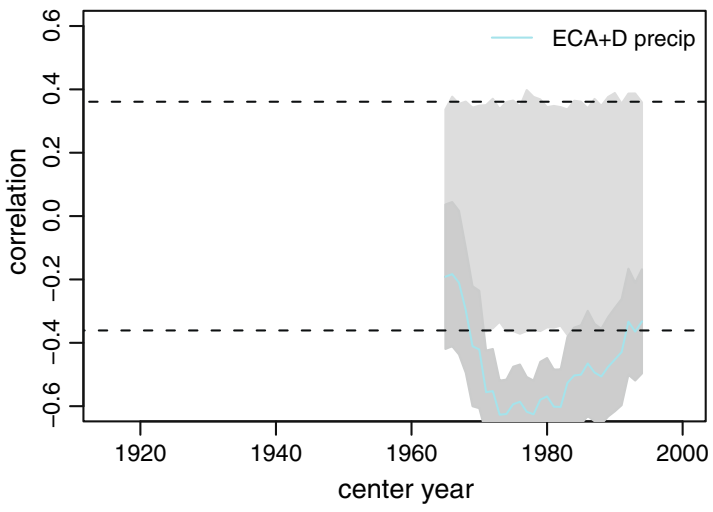

French domain: running precip(MAM), precip(SON) correlation (30 years)

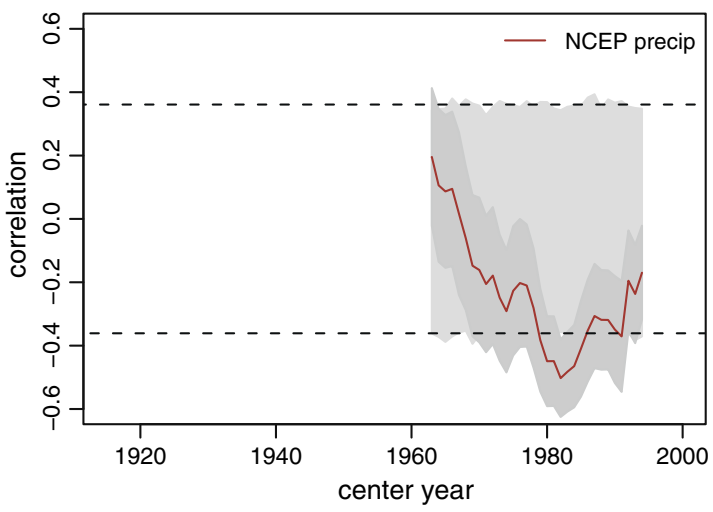

GPCC, the $95 \%$ confidence interval from the pair-wise resampling of 30 years from the whole time series is denoted by the horizontal grey lines, and the median and the 95\% confidence intervals of the minimum correlations from the parametric bootstrap are displayed by the bars on the left in the respective panels. Center year denotes year 16 of the 30 -year time window

Risks and Effects, Christensen et al. 2007) and from the CMIP3 archive are investigated. AMIP simulations are constrained by observed SST and sea ice boundary 
conditions (Rayner et al. 2003; Hurrell et al. 2008). The PRUDENCE AMIP simulations are exclusively available for 1961-1990, and the CMIP3 AMIP simulations for approximately 1979-2003 (depending on the model).

We also analyze the regional climate model (RCM) simulations from the EU-projects PRUDENCE and ENSEMBLES. The PRUDENCE RCMs (with spatial resolutions of approximately $50 \mathrm{~km}$ ) are all driven by the same respective boundary conditions from the global model HadAM3H $\left(1.875 \times 1.25^{\circ}\right.$ resolution $)$. The analyzed ENSEMBLES RCMs (with spatial resolutions of approximately $25 \mathrm{~km}$ ) are driven by ERA-40 boundary conditions, which realistically represent the large-scale atmospheric circulation. The PRUDENCE simulations are exclusively available for 1961-1990, while the ENSEMBLES simulations are available for approximately 1961-2000 (depending on the model).

None of the analyzed GCM simulations (except for GFDL CM2.1, which shows a significantly negative signal for a short time), nor the GCM-driven PRUDENCE RCMs exhibit the observed temporal evolution of

French domain: running precip(MAM), precip(SON) correlation (30 years)

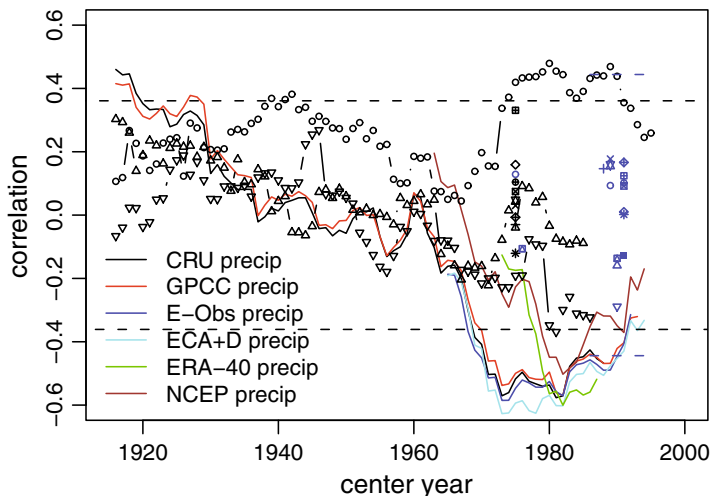

$$
\begin{aligned}
& \text { AR4 GCMs } \\
& \circ \text { ECHAM5 } \\
& \nabla \text { GFDL CM2.1 } \\
& \triangle \text { HadGEM1 } \\
&+ \text { CCCma CGCM3.1 } \\
& \times \text { GISS ER } \\
& \diamond \text { HadCM3 } \\
& \otimes \text { INM CM3 } \\
& * \text { IPSL CM4 } \\
& \otimes \text { MIROC3.2 medres } \\
& \oplus \text { MRI CGCM2.3.2 } \\
& \otimes \text { NCAR CCSM } \\
& \boxplus \text { NCAR PCM }
\end{aligned}
$$

spring-to-autumn precipitation correlation, nor the significantly negative correlations (see Fig. 2, the 5\% significance level for the two-tailed test is again displayed as black dashed lines). The only models displaying the significantly negative spring-to-autumn link are ENSEMBLES RCMs driven by realistic ERA-40 boundary conditions (although not all of them are showing this link,

\begin{tabular}{|c|c|}
\hline PRUDENCE RCMs & ENSEMBLES RCMs \\
\hline$+\mathrm{CHRM}$ & + CLM \\
\hline$\times$ ARPEGE & $\times$ RACMO \\
\hline$\diamond$ HIRHAM & Aladin \\
\hline$\triangle$ CLM & $\triangle \mathrm{RegCM}$ \\
\hline * HadRM & * RCA \\
\hline$\Leftrightarrow$ RegCM & $\Leftrightarrow$ HadRM \\
\hline$\oplus$ RACMO & $\oplus$ REMO \\
\hline$\$ \triangle$ REMO & RCA3 \\
\hline$\boxplus \mathrm{RCAO}$ & \\
\hline PROME & \\
\hline
\end{tabular}
and most of those that do to a lesser extent than the observations). Note that for the CMIP3 AMIP simulations only approximately 20 years of data are available (the 5\% significance level for the two-tailed test is represented by the short blue dashed lines for these models).

\section{Discussion}

The results of the previous section raise two questions: What is the mechanism underlying the temporal evolution of the observed correlations and the negative correlations in the second half of the twentieth century? And why do most models fail to catch the described phenomenon?

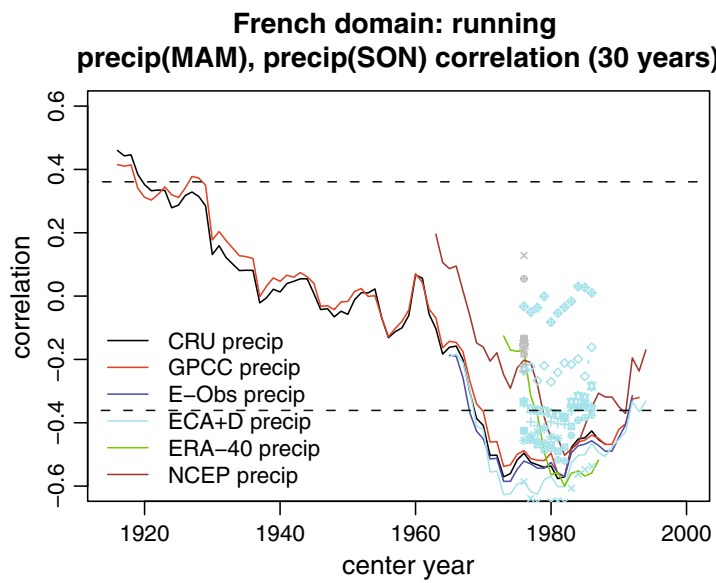

Fig. 2 Temporal evolution of the 30-year spring-to-autumn precipitation correlation in France (domain: see Fig. 5) for the different observational datasets and the ERA-40 and NCEP/NCAR reanalyses, as well as for the analyzed model datasets: (left) GCMs, (right) RCMs. The theoretical 5\% significance level (two-tailed test) is

displayed as black dashed lines (30-year correlation), and as short blue dashed lines for the CMIP3 AMIP simulations (20-year correlation, see text). Center year denotes year 16 of the 30 -year time window 


\subsection{Mechanisms}

In the following, we focus on the analysis of the negative correlations in the second half of the twentieth century. To analyze the influence of the large-scale circulation on the observed precipitation link, the running 30-year correlation is applied to different MSLP datasets averaged over France, i.e., observed MSLP from Trenberth and Paolino (1980) and HadSLP2 (Allan and Ansell 2006), as well as ERA-40 and NCEP/NCAR reanalyses MSLP. The running correlation between spring and autumn MSLP reveals the same temporal evolution as for precipitation in France (Fig. 3), with a downward trend and significantly negative correlations in the second half of the twentieth century, and indications of a beginning upward trend at the end of the century. Note that as for precipitation, the extension of the domain to the whole of Central Europe (same domain as in Hirschi et al. 2007) reveals the same temporal evolution of the MSLP correlations including (slightly less pronounced) significantly negative correlations in the second half of the twentieth century. Also note that the running 30-year in-season correlations between MSLP and precipitation are significantly negative for both spring and autumn during the entire twentieth century.

\section{French domain: running MSLP(MAM), MSLP(SON) correlation (30 years)}

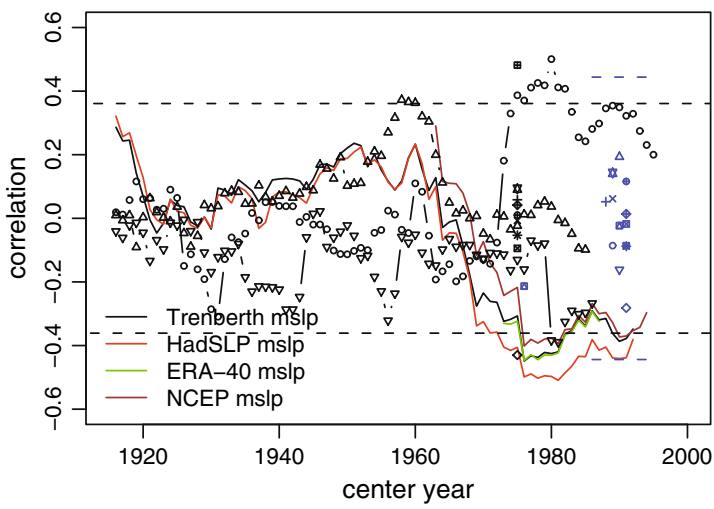

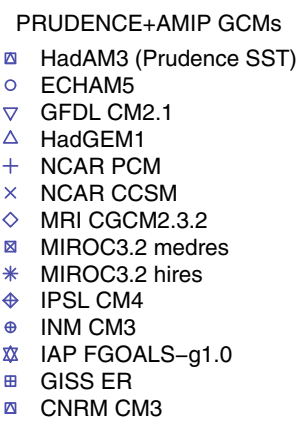

Fig. 3 Temporal evolution of the 30-year spring-to-autumn MSLP correlation in France (domain: see Fig. 5) for the two observational datasets and the ERA-40 and NCEP/NCAR reanalyses, as well as for the analyzed model datasets: (left) GCMs, (right) RCMs. The
Moreover, preferred modes of the low-frequency variability of the atmosphere can be identified by the $500 \mathrm{hPa}$ geopotential height loading patterns using rotated principal component analysis (Barnston and Livezey 1987), and expressed as teleconnection indices (available at http:// www.cpc.ncep.noaa.gov/data/teledoc/telecontents.shtml for the period 1950-present). In the second half of the twentieth century, precipitation over France is significantly positively correlated with the EA pattern index in spring, and with the SCA pattern index in autumn (with 30-year correlations of $\sim 0.5$ and $\sim 0.7$, respectively). The running 30 -year correlation between the spring EA pattern and the autumn SCA pattern reveals again a similar temporal evolution as for the precipitation analysis in France (note that the pattern data is only available after 1950, see Fig. 4). Other patterns may be associated with precipitation over France as well (e.g., the NAO and the East Atlantic/ West Russia (Eurasia-2) patterns), however, no combination of these exhibits a comparably significant spring-toautumn link (not shown).

Also the effects of the North Atlantic SST on precipitation in Europe have been investigated (RodríguezFonseca et al. 2006). On decadal timescales, observational studies have shown evidence for a SST forcing of the

\section{French domain: running MSLP(MAM), MSLP(SON) correlation (30 years)}

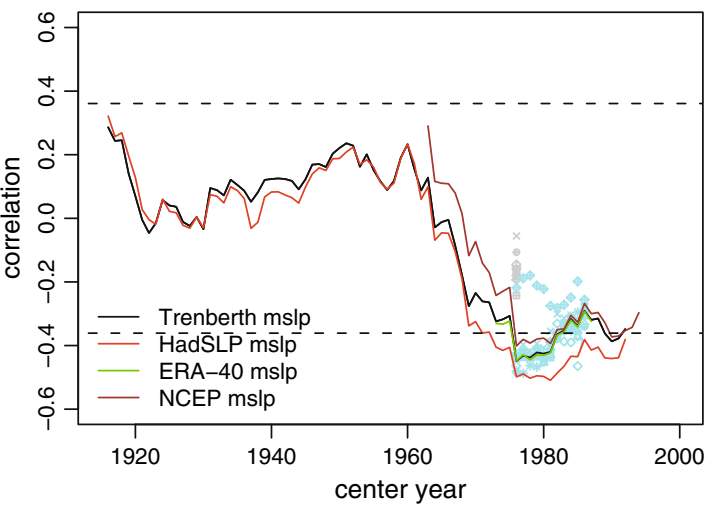

\begin{tabular}{|c|c|c|c|}
\hline \multicolumn{2}{|c|}{ PRUDENCE RCMS } & \multicolumn{2}{|c|}{ ENSEMBLES RCMs } \\
\hline & CHRM & & CLM \\
\hline$x$ & ARPEGE & $x$ & RACMO \\
\hline$\diamond$ & HIRHAM & $\diamond$ & Aladin \\
\hline$凶$ & CLM & 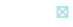 & RegCM \\
\hline * & HadRM & * & RCA \\
\hline$\oplus$ & RegCM & $\ominus$ & HadRM \\
\hline$\oplus$ & RACMO & $\oplus$ & REMO \\
\hline 88 & REMO & 88 & RCA3 \\
\hline 田 & $\mathrm{RCAO}$ & & \\
\hline 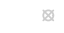 & PROMES & & \\
\hline
\end{tabular}

theoretical 5\% significance level (two-tailed test) is displayed as black dashed lines (30-year correlation), and as short blue dashed lines for the CMIP3 AMIP simulations (20-year correlation, see text). Center year denotes year 16 of the 30 -year time window 


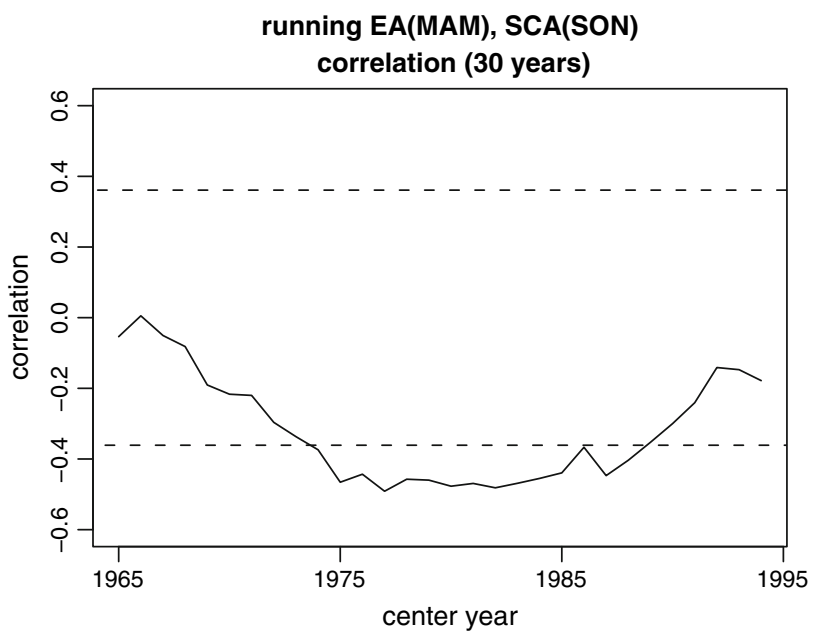

Fig. 4 Temporal evolution of the 30-year spring-to-autumn correlation of the spring East Atlantic (EA) pattern and the autumn Scandinavian (SCA) pattern

atmospheric circulation in the North Atlantic region (e.g., Sutton and Allen 1997; Rodwell and Folland 2002). Rodríguez- Fonseca and de Castro (2002) showed that NAO-linked extreme winter precipitation events in the Iberian Peninsula and Northern Africa are connected with an anomalous SST pattern that persists from the previous summer months and influences the atmospheric circulation.

Here, the relation of North Atlantic/Mediterranean SST (from the HadISST dataset, Rayner et al. 2003) anomaly patterns with precipitation, MSLP and teleconnection indices is investigated by means of maximum covariance analyses (MCA, see e.g., Wilks 2006). These analyses (Fig. 5) reveal for the period 1971-2000 that, both for the spring and autumn, the in-season SST anomaly patterns (top two rows) linked with precipitation (left) and MSLP (middle) show very similar structures (with opposite sign). Note that similar SST patterns emerge regarding links to the SCA pattern index in autumn, and, to a lesser extent, also to the EA index in spring. These SST patterns consist of a center of action southeast of Newfoundland (which seems to expand from spring to autumn), and regions of opposite sign to the west and east thereof. A similar SST pattern, derived from a MCA of winter precipitation over Europe and Northern Africa and previous summer SST, has also been described by Rodríguez-Fonseca et al. (2006). Moreover, spring precipitation and spring MSLP are connected with the same autumn SST pattern as that identified for the in-season MCA (Fig. 5, bottom row), indicating that at least part of the spring-to-autumn link is mediated through SST. Looking at these relationships in the period 1931-1960, the spring-to-autumn connection over SST does not appear as distinct anymore, while the in-season SST patterns are similar in both periods (not shown)
To further investigate the simultaneity of the above links between spring and autumn on a yearly basis, we define yearly spring-to-autumn indices (indicative of the contribution of single-year links to the overall correlation):

Precipitation:

$$
P . \text { index }=P_{(\mathrm{MAM})}^{\prime} / \sigma_{P_{(\mathrm{MAM})}} * P_{(\mathrm{SON})}^{\prime} / \sigma_{P_{(\mathrm{SON})}}
$$

MSLP:

$$
\begin{aligned}
M S L P . \text { index }= & M S L P_{(\mathrm{MAM})}^{\prime} / \sigma_{M S L P_{(\mathrm{MAM})}} \\
& * M S L P_{(\mathrm{SON})}^{\prime} / \sigma_{M S L P_{(\mathrm{SON})}}
\end{aligned}
$$

Teleconnection pattern indices:

$$
\begin{aligned}
\text { PATTERN.index }= & E A_{(\mathrm{MAM})}^{\prime} / \sigma_{E A_{(\mathrm{MAM})}} \\
& * S C A_{(\mathrm{SON})}^{\prime} / \sigma_{S C A_{(\mathrm{SON})}}
\end{aligned}
$$

Spring precipitation and autumn SST (1st mode expansion coefficients from the corresponding MCA):

$$
P . S S T \text {.index }=P_{(\mathrm{MAM})}^{\prime} / \sigma_{P_{(\mathrm{MAM})}} * S S T_{(\mathrm{SON})}^{\prime} / \sigma_{S S T_{(\mathrm{SON})}}
$$

Spring MSLP and autumn SST (1st mode expansion coefficients from the corresponding MCA):

$$
\begin{aligned}
M S L P . S S T . i n d e x= & M S L P_{(\mathrm{MAM})}^{\prime} / \sigma_{M S L P_{(\mathrm{MAM})}} \\
& * S S T_{(\mathrm{SON})}^{\prime} / \sigma_{S S T_{(\mathrm{SON})}}
\end{aligned}
$$

Note that the prime $(')$ refers to the seasonal anomaly and $\sigma$ to the standard deviation of the respective variables. The temporal evolution of these yearly indices is shown in Fig. 6 (top five panels). The application of a 30-year running mean on the indices reveals the same temporal evolution as for the running 30-year correlations of precipitation, MSLP and the teleconnection pattern indices (downward trend and negative values in the second half of the twentieth century).

When applying a multiple linear regression for the period 1950-2002 with these indices, the following model results:

$$
\begin{aligned}
\text { P.index }= & -0.02+0.57 * \text { MSLP.index } \\
& +0.22 * \text { PATTERN.index } \\
& -0.24 * P . S S T . i n d e x \\
& +0.53 * \operatorname{resid}(\text { MSLP.SST.index } \sim P . S S T . \text { index })
\end{aligned}
$$

To avoid the co-linearity between P.SST.index and MSLP.SST.index, the latter has been replaced by the residuals of a regression of P.SST.index on MSLP.SST.index, i.e., through the part of MSLP.SST. index that is not explained by P.SST.index (denoted resid(MSLP.SST.index $\sim$ P.SST.index) in Eq. 6). All terms appear significant in the model, with an overall fraction 

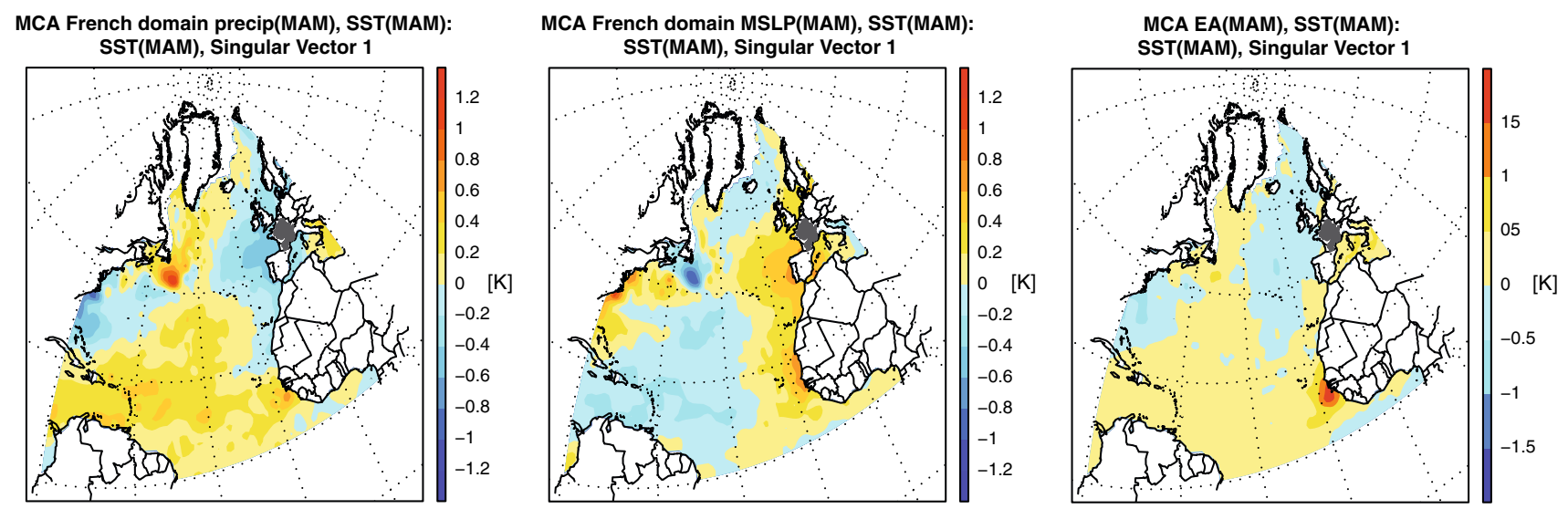

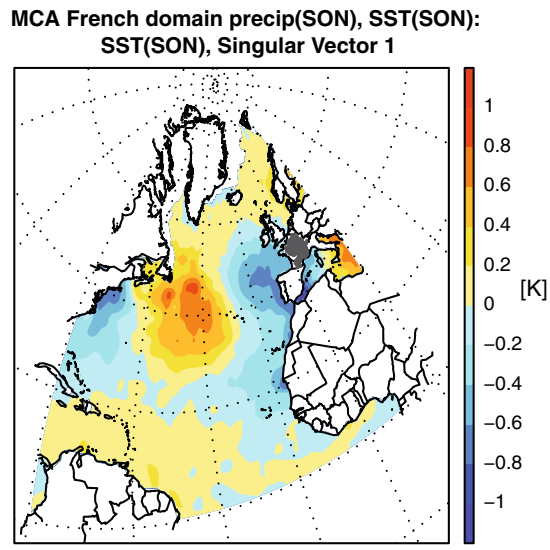

MCA French domain MSLP(SON), SST(SON): SST(SON), Singular Vector 1

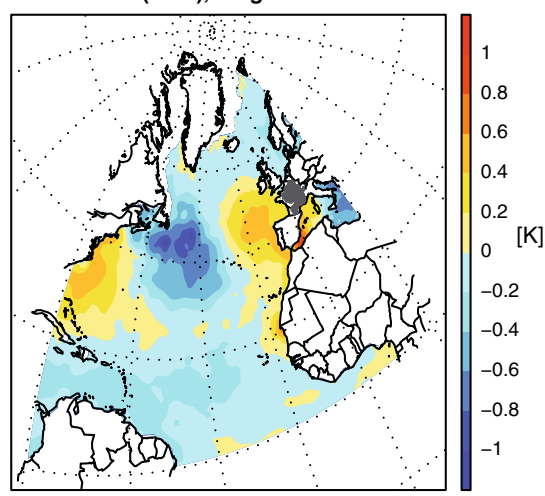

MCA French domain MSLP(MAM), SST(SON):

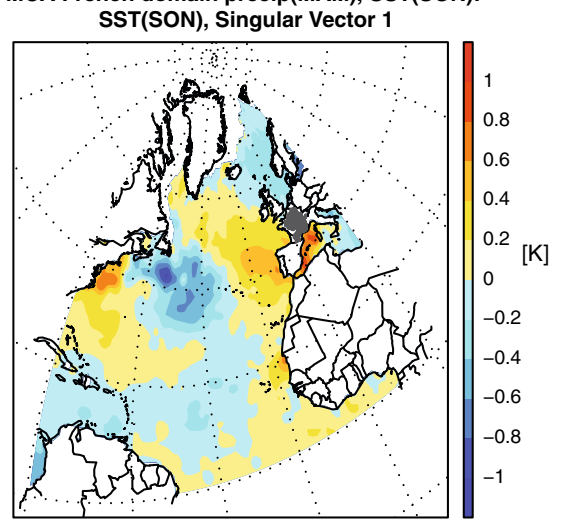
SST(SON), Singular Vector 1

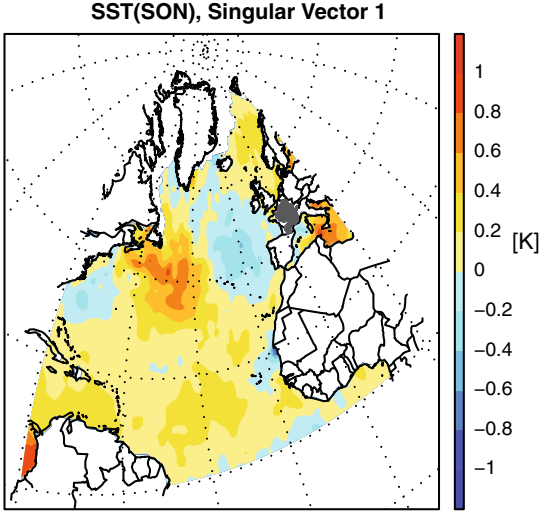

Fig. 5 (Top two rows) In-season MCA of SST with (left) precipitation, (middle) MSLP (both averaged over France, dark grey domain), and (right) the EA and SCA pattern indices for spring and autumn and the period 1971-2000. (Bottom row) MCA of (left) spring

of explained variance of $R^{2}=0.56$. The agreement between the observed and the modeled link in precipitation is displayed in the bottom panel of Fig. 6 . Note that there appears to be no co-linearity between the two regressors MSLP.index and PATTERN.index $\left(R_{x}^{2}=\right.$ 0.003). This is due to the fact that the EA pattern shows no significant correlation with MSLP over France, as the domain is situated between the two anomaly centers of precipitation and (right) spring MSLP with autumn SST for the same period. Shown are the SST singular vectors of the corresponding 1st modes, scaled by the standard deviation of the respective expansion coefficients

the pattern. Overall, the regression model indicates that a substantial part of the yearly spring-to-autumn link in precipitation appears in-line with simultaneous spring-toautumn links in MSLP and in the teleconnection patterns, as well as between spring precipitation/MSLP and autumn SST. However, note that this does not necessarily imply causality (e.g., Orlowsky and Seneviratne 2009). 


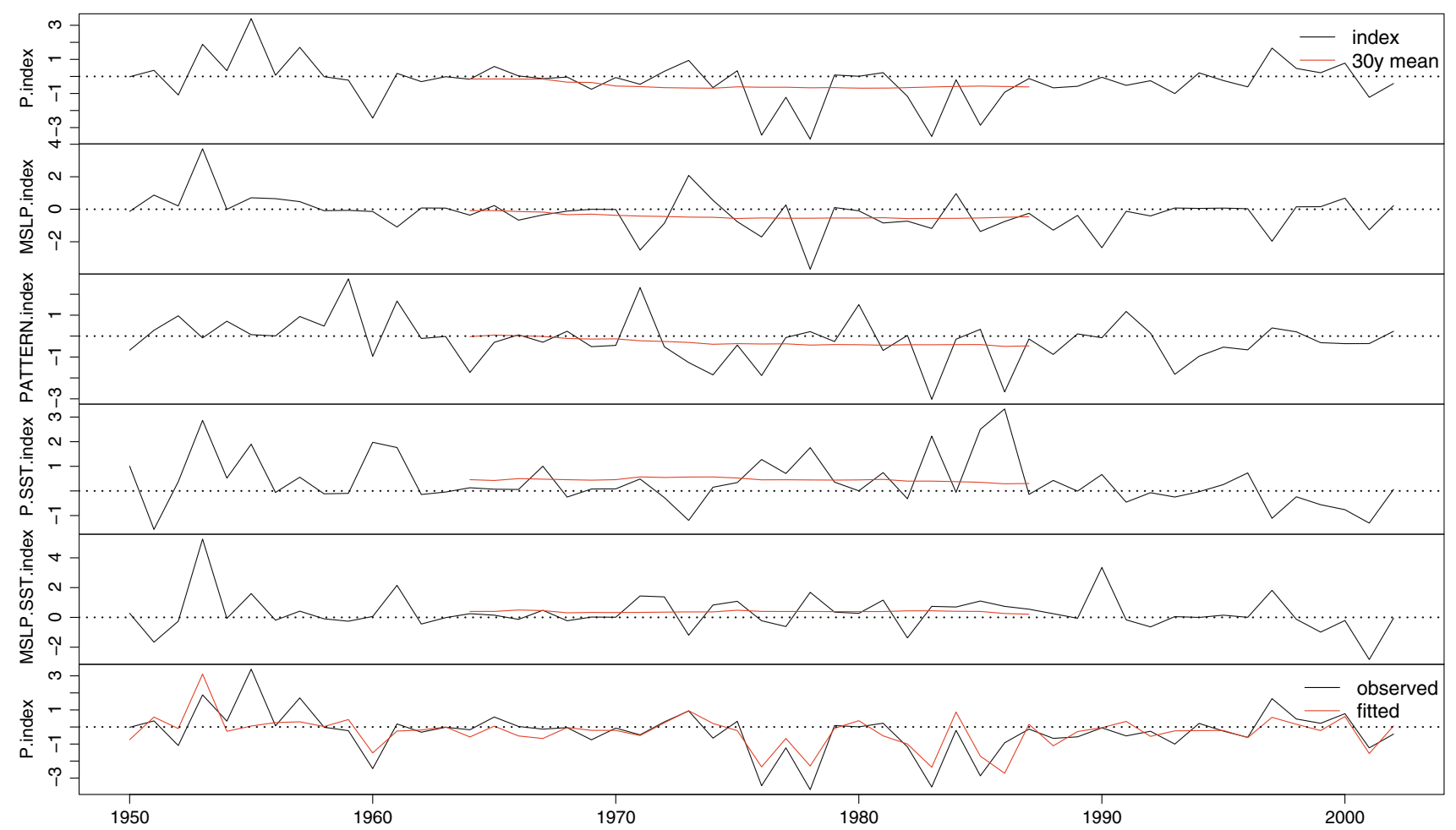

Fig. 6 Yearly indices of the spring-to-autumn links in (from top) precipitation, MSLP, geopotential height patterns (spring EA pattern and autumn SCA pattern), spring precipitation and autumn SST, and

\subsection{Possible explanations for model-data disagreement}

To investigate the failure of the models in simulating the observed spring-to-autumn link in precipitation, we apply the running 30-year correlations to the modeled MSLP (in the same way as for the observed and the ERA-40 and NCEP/NCAR reanalyses MSLP above). As for precipitation, most GCM simulations and the GCM-driven PRUDENCE RCMs are not able to reproduce the observed link between spring and autumn MSLP (except for HadCM3 and GFDL CM2.1 which show a significantly negative signal, see below and Fig. 3). Given the influence of MSLP on the observed precipitation link (see section above), the absence of the MSLP link in the models leads to their consequent failure to simulate the precipitation link. While the negative MSLP signal of GFDL CM2.1 is consistent with its signal in precipitation and with the observations (negatively correlated spring-to-autumn values in both variables), the behavior of HadCM3 is surprising since it only shows negative spring-to-autumn correlations in MSLP but not in precipitation (see Fig. 2). As the in-season correlations between MSLP and precipitation are consistent between HadCM3 and the observations (significantly negatively correlated both in spring and autumn, not shown), other processes might dominate the link in precipitation in this model (note that the fraction of variance spring MSLP and autumn SST, as well as observed and fitted precipitation index. The top five panels also show the 30-year running mean of the index (red)

that is explained by the MSLP link is around 0.3 in the regression model of the previous section). Again, the only models that are consistent with the observed MSLP link are the ERA-40 driven ENSEMBLES RCMs (except for HadRM). They follow closely the MSLP link of ERA-40 and seem strongly influenced by the ERA- 40 boundary forcing.

The reason for the failure of most models in simulating the identified link in MSLP and the associated atmospheric circulation is not clear at this stage and identifying it is beyond the scope of this investigation. However, the positive phase of the SCA pattern is associated with positive height anomalies over Scandinavia and western Russia, which sometimes reflect major blocking anticyclones. It has been shown that regional mid- and high-latitude precipitation is strongly affected by the presence of atmospheric blocking activity, and that climate models undersimulate such activity (van Ulden and van Oldenborgh 2006; Palmer et al. 2008). This in turn might result in a wrong frequency of autumn precipitation in the models and thereby affect their intra-annual variability of precipitation.

Furthermore, the temporal evolution (downward trend followed by beginning upward trend) of the observed spring-to-autumn correlations of precipitation and MSLP coincides with the solar dimming (before $\sim 1985$ ) and brightening (after $\sim 1985$ ) phases reported in recent 
publications (e.g., Norris and Wild 2007; Wild et al. 2007). These trends in shortwave radiation are connected with changes in anthropogenic aerosol emissions that led to more scattering and absorption of shortwave radiation during the earlier period of solar dimming, and less scattering and absorption during the later period of solar brightening (Norris and Wild 2007). Most presently available climate models do not include the full range of aerosol processes (e.g., Knutti 2008). This means that they do not incorporate aerosol effects on climate beyond the direct (scattering and absorption of solar radiation; scattering, absorption and emittance of thermal radiation) and the first indirect (cloud albedo enhancement of warm clouds) effects (e.g., Lohmann and Feichter 2005). However, these further effects influence precipitation (for an overview on the multitude of aerosol effects see e.g., Lohmann and Feichter 2005) and thus might affect the ability of the models to reproduce the observed spring-toautumn link in precipitation. We also analyzed a freerunning stable ECHAM-MLO coupled simulation, which includes an additional aerosol module that simulates indirect aerosol effects, but does nonetheless not exhibit the negative spring-to-autumn link (not shown here). However, one has to note that this simulation was not driven with observed SST.

Moreover, the ERA-40 reanalysis shows both the link in MSLP and consequently in precipitation (with a temporal delay of about 10 years, see Figs. 1, 3). ERA-40 is not only constrained by observed SST (as the AMIP-style GCMs), but includes various assimilated surface and atmospheric observations (e.g., SYNOP, radiosondes, aircraft, satellite; Uppala et al. 2005). Although precipitation itself is not an assimilated variable in ERA-40, the assimilation of other observations seems to help the ERA-40 reanalysis to capture the right precipitation link. This is supported by the fact that the column integrated atmospheric moisture convergence over France, which is expected to be close to observations thanks to the assimilation of radiosonde measurements of the atmospheric moisture content and wind, shows consistently negative correlations between spring and autumn (Fig. 7). The delay in the onset of the significantly negative correlations in the ERA-40 and NCEP/NCAR reanalyses might possibly be related to the introduction of the assimilation of the satellite data in the 1970s.

\section{Conclusion}

We presented and analyzed an intra-annual relationship of observed precipitation over France, which is manifested by significantly negative spring-to-autumn correlations in the second half of the twentieth century. These correlations
French domain: running

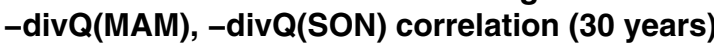

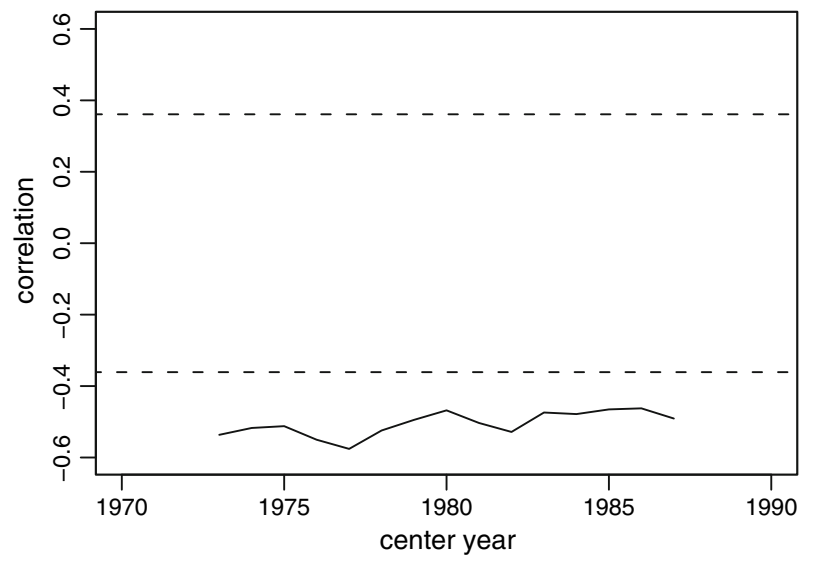

Fig. 7 Temporal evolution of the 30-year spring-to-autumn correlation of ERA-40 column integrated atmospheric moisture convergence over France (domain: see Fig. 5)

appear to be connected with significantly negative springto-autumn correlations in observed MSLP, and with the significantly negatively correlated spring EA and autumn SCA teleconnection patterns. Analyses of SST patterns with these atmospheric variables by means of MCA indicate that at least part of the spring-to-autumn link is mediated through SST, as spring precipitation and MSLP are linked with the same autumn SST pattern as are autumn precipitation, MSLP and the SCA pattern index.

Except for ERA-40 driven ENSEMBLES RCMs, the analyzed regional and global climate models are not able to simulate this observed variability in precipitation, which is associated with the failure of most models in simulating the observed correlations between spring and autumn MSLP. Possible reasons for the non-representation of this effect in the models have been proposed and include the underestimation of the atmospheric blocking frequency and the neglecting of aerosol effects on climate beyond the direct and the first indirect aerosol effects. We cannot fully exclude that the occurrence of this relationship may be due to climate noise, however, this explanation seems unlikely given the strength of the signal and the fact that the signal is found over a 30 -year period.

The question of why the correlation between spring and autumn precipitation (and MSLP) shifts from positive to negative values during the twentieth century remains open. Sutton and Hodson $(2005,2007)$ analyzed the influence of basin-scale changes in the Atlantic Ocean on multidecadal variations in regional climate over Europe. These changes are associated with the Atlantic Multidecadal Oscillation (AMO; Delworth and Mann 2000; Kerr 2000), which describes a temperature oscillation in the North Atlantic with a period of 65-80 years (Schlesinger and Ramankutty 
1994; Enfield et al. 2001). Recently, Baines and Folland (2007) also provided evidence for a rapid global shift in climate across the late 1960s, which is visible in a nearmonotonic change of different climate variables. The most likely causes for this shift appeared to be a reduction in the northward oceanic heat flux associated with the North Atlantic thermohaline circulation in the 1950 s to 1970 s, which is related to the above described AMO, and which was nearly in phase with a rapid increase in anthropogenic aerosol emissions during the 1950s and 1960s. The temporal concurrence of this shift in climate with the observed shift to negative correlations between spring and autumn precipitation is an indication that the causes for the climate shift could also be connected with the temporal evolution of the precipitation correlations.

These studies mostly analyzed the inter-decadal response in the mean (annual or seasonal) of different climate variables, but not their change in variability. At this point, one can only speculate on the contribution of such mechanisms to the observed temporal evolution of the intra-annual link of spring and autumn precipitation over France, and the connected links of MSLP and the EA and SCA teleconnection patterns. However, assuming such a contribution, and given the possible role of aerosols in the described climate shift, the non-representation of the full range of aerosol processes in most climate models might also affect their ability to simulate the observed temporal evolution of the identified spring-to-autumn relationships.

Acknowledgments We acknowledge the use of the datasets from the Climate Prediction Center, the CRU, the ECMWF, the GPCC, the Hadley Centre, the Data Support Section at the NCAR, NOAA-ESRL Physical Sciences Division, the E-Obs dataset from the EU-FP6 project ENSEMBLES (http://www.ensembles-eu.org) and the data providers in the ECA\&D project (http://eca.knmi.nl). Moreover, we would like to thank the PRUDENCE and ENSEMBLES communities, Martin Wild (for the PRUDENCE-SST ECHAM run), Sylvaine Ferrachat (for the ECHAM-MLO experiments) for providing model data. We acknowledge the modeling groups, the Program for Climate Model Diagnosis and Intercomparison (PCMDI) and the WCRP's Working Group on Coupled Modelling (WGCM) for their roles in making available the WCRP CMIP3 multi-model dataset. Support of this dataset is provided by the Office of Science, U.S. Department of Energy. We also thank Stefan Brönnimann, Thierry Corti, Ulrike Lohmann, Boris Orlowsky, Reinhard Schiemann and Martin Wild for helpful discussions. Christoph Frei is gratefully acknowledged for the provision of the R-package pcaXcca used for the MCA. Moreover, we thank the anonymous reviewers for their valuable comments.

\section{References}

Allan R, Ansell T (2006) A new globally complete monthly historical gridded mean sea level pressure dataset (HadSLP2): 1850-2004. J Clim 19(22):5816-5842

Baines PG, Folland CK (2007) Evidence for a rapid global climate shift across the late 1960s. J Clim 20(12):2721-2744
Barnston AG, Livezey RE (1987) Classification, seasonality and persistence of low-frequency atmospheric circulation patterns. Mon Weather Rev 115(6):1083-1126

Casty C, Raible C, Stocker T, Wanner H, Luterbacher J (2007) A European pattern climatology 1766-2000. Clim Dyn 29(7):791805

Christensen JH, Carter TR, Rummukainen M, Amanatidis G (2007) Evaluating the performance and utility of regional climate models: the PRUDENCE project. Clim Change 81(Suppl 1): $1-6$

Delworth TL, Mann ME (2000) Observed and simulated multidecadal variability in the Northern Hemisphere. Clim Dyn 16(9):661676

Enfield DB, Mestas-Nuñez AM, Trimble PJ (2001) The Atlantic Multidecadal Oscillation and its relation to rainfall and river flows in the continental U.S. Geophys Res Lett 28(10):20772080

Fischer EM, Seneviratne SI, Lüthi D, Schär C (2007) Contribution of land-atmosphere coupling to recent European summer heat waves. Geophys Res Lett 34(L06707). doi:10.1029/2006GL029,068

Haylock MR, Hofstra N, Klein Tank AMG, Klok EJ, Jones PD, New M (2008) A European daily high-resolution gridded dataset of surface temperature and precipitation for 1950-2006. J Geophys Res 113(D20119). doi:10.1029/2008JD010,201

Hirschi M, Seneviratne SI, Hagemann S, Schär C (2007) Analysis of seasonal terrestrial water storage variations in regional climate simulations over Europe. J Geophys Res 112(D22109). doi: 10.1029/2006JD008,338

Hurrell JW (1995) Decadal trends in the North Atlantic Oscillation: regional temperatures and precipitation. Science 269(5224):676679

Hurrell JW, van Loon H (1997) Decadal variations in climate associated with the North Atlantic Oscillation. Clim Change 36(3-4):301-326

Hurrell JW, Kushnir Y, Ottersen G, Visbeck M (2003) An overview of the North Atlantic Oscillation. In: Hurrell J, Kushnir Y, Ottersen G, Visbeck M (ed) The North Atlantic Oscillation: climatic significance and environmental impact, no. 134 in Geophysical Monograph Series. American Geophysical Union, Washington, DC

Hurrell JW, Hack JJ, Shea D, Caron JM, Rosinski J (2008) A new sea surface temperature and sea ice boundary dataset for the community atmosphere model. J Clim 21(19):5145-5153

Kerr RA (2000) A North Atlantic climate pacemaker for the centuries. Science 288(5473):1984-1985

Klein Tank AMG, Wijngaard JB, Können GP, Böhm R, Demarée G, Gocheva A, Mileta M, Pashiardis S, Hejkrlik L, Kern-Hansen C, Heino R, Bessemoulin P, Müller-Westermeier G, Tzanakou M, Szalai S, Pálsdóttir T, Fitzgerald D, Rubin S, Capaldo M, Maugeri M, Leitass A, Bukantis A, Aberfeld R, van Engelen AFV, Forland E, Mietus M, Coelho F, Mares C, Razuvaev V, Nieplova E, Cegnar T, Antonio López J, Dahlström B, Moberg A, Kirchhofer W, Ceylan A, Pachaliuk O, Alexander LV, Petrovic P (2002) Daily dataset of 20th-century surface air temperature and precipitation series for the European Climate Assessment. Int J Climatol 22(12):1441-1453

Knutti R (2008) Why are climate models reproducing the observed global surface warming so well? Geophys Res Lett 35(L18704). doi:10.1029/2008GL034,932

Koster RD, Suarez MJ, Heiser M (2000) Variance and predictability of precipitation at seasonal-to-interannual timescales. J Hydrometeorol 1:26-46

Koster RD, Dirmeyer PA, Guo Z, Bonan G, Chan E, Cox P, Gordon CT, Kanae S, Kowalczyk E, Lawrence D, Liu P, Lu CH, Malyshev S, McAvaney B, Mitchell K, Mocko D, Oki T, Oleson K, Pitman A, Sud YC, Taylor CM, Verseghy D, Vasic R, Xue Y, 
Yamada T (2004) Regions of strong coupling between soil moisture and precipitation. Science 305(5687):1138-1140

Lohmann U, Feichter J (2005) Global indirect aerosol effects: a review. Atmos Chem Phys 5(3):715-737

Massei N, Durand A, Deloffre J, Dupont JP, Valdes D, Laignel B (2007) Investigating possible links between the North Atlantic Oscillation and rainfall variability in northwestern France over the past 35 years. J Geophys Res 112(D09121). doi:10.1029/ 2005JD007,000

Mitchell TD, Jones PD (2005) An improved method of constructing a database of monthly climate observations and associated highresolution grids. Int J Climatol 25:693-712. doi:10.1002/ joc. 1181

Norris JR, Wild M (2007) Trends in aerosol radiative effects over Europe inferred from observed cloud cover, solar "dimming," and solar "brightening". J Geophys Res 112(D08214). doi: 10.1029/2006JD007,794

Orlowsky B, Seneviratne SI (2009) Statistical analyses of landatmosphere feedbacks and their possible pitfalls. J Clim (submitted)

Palmer TN, Doblas-Reyes RJ, Weisheimer A, Rodwell MJ (2008) Toward seamless prediction: calibration of climate change projections using seasonal forecasts. Bull Am Meteorol Soc 89(4):459-470

Pauling A, Luterbacher J, Casty C, Wanner H (2006) Five hundred years of gridded high-resolution precipitation reconstructions over Europe and the connection to large-scale circulation. Clim Dyn 26(4):387-405

Rayner NA, Parker DE, Horton EB, Folland CK, Alexander LV, Rowell DP, Kent EC, Kaplan A (2003) Global analyses of sea surface temperature, sea ice, and night marine air temperature since the late nineteenth century. J Geophys Res 108(D14). doi: 10.1029/2002JD002,670

Rodríguez-Fonseca B, de Castro M (2002) On the connection between winter anomalous precipitation in the Iberian Peninsula and North West Africa and the summer subtropical Atlantic sea surface temperature. Geophys Res Lett 29(18). doi:10.1029/ 2001GL014,421

Rodríguez-Fonseca B, Polo I, Serrano E, Castro M (2006) Evaluation of the North Atlantic SST forcing on the European and Northern African winter climate. Int J Climatol 26(2):179-191

Rodwell MJ, Folland CK (2002) Atlantic air-sea interaction and seasonal predictability. Q J R Meteorol Soc 128(583):1413-1443

Rudolf B, Hauschild H, Rueth W, Schneider U (1994) Terrestrial precipitation analysis: operational method and required density of point measurements. In: Desbois M, Desalmand F (eds) Global precipitations and climate change, NATO ASI series I, vol 26. Springer, Berlin, pp 173-186

Schlesinger ME, Ramankutty N (1994) An oscillation in the global climate system of period 65-70 years. Nature 367(6465): 723-726

Schubert SD, Suarez MJ, Pegion PJ, Koster RD, Bacmeister JT (2008) Potential predictability of long-term drought and pluvial conditions in the U.S. Great Plains. J Clim 21(4):802-816

Seneviratne SI, Koster RD, Guo Z, Dirmeyer PA, Kowalczyk E, Lawrence D, Liu P, Lu CH, Mocko D, Oleson KW, Verseghy D (2006a) Soil moisture memory in AGCM simulations: analysis of global land-atmosphere coupling experiment (GLACE) data. J Hydrometeorol 7(5):1090-1112

Seneviratne SI, Lüthi D, Litschi M, Schär C (2006b) Landatmosphere coupling and climate change in Europe. Nature 443(7108):205-209
Seneviratne SI, Corti T, Davin EL, Hirschi M, Jaeger EB, Lehner I, Orlowsky B, Teuling AJ (2009) Investigating soil moistureclimate interactions in a changing climate: a review. Earth-Sci Rev (submitted)

Sutton RT, Allen MR (1997) Decadal predictability of North Atlantic sea surface temperature and climate. Nature 388(6642):563-567

Sutton RT, Hodson DLR (2003) Influence of the ocean on North Atlantic climate variability 1871-1999. J Clim 16(20):3296-3313

Sutton RT, Hodson DLR (2005) Atlantic ocean forcing of North American and European summer climate. Science 309(5731): $115-118$

Sutton RT, Hodson DLR (2007) Climate response to basin-scale warming and cooling of the North Atlantic Ocean. J Clim 20(5):891-907

Trenberth K, Paolino D (1980) The Northern Hemisphere sea level pressure data set: trends, errors, and discontinuities. Mon Weather Rev 108:855-872

Trigo RM, Osborn TJ, Corte-Real JM (2002) The North Atlantic Oscillation influence on Europe: climate impacts and associated physical mechanisms. Clim Res 20(1):9-17

Uppala S, Kållberg P, Simmons A, Andrae U, da Costa Bechtold V, Fiorino M, Gibson J, Haseler J, Hernandez A, Kelly G, Li X, Onogi K, Saarinen S, Sokka N, Allan R, Andersson E, Arpe K, Balmaseda M, Beljaars A, van de Berg L, Bidlot J, Bormann N, Caires S, Chevallier F, Dethof A, Dragosavac M, Fisher M, Fuentes M, Hagemann S, Holm E, Hoskins B, Isaksen L, Janssen P, Jenne R, McNally A, Mahfouf JF, Morcrette JJ, Rayner N, Saunders R, Simon P, Sterl A, Trenberth K, Untch A, Vasiljevic D, Viterbo P, Woollen J (2005) The ERA-40 re-analysis. Q J R Meteorol Soc 131(612):2961-3012

van Ulden AP, van Oldenborgh GJ (2006) Large-scale atmospheric circulation biases and changes in global climate model simulations and their importance for climate change in Central Europe. Atmos Chem Phys 6(4):863-881

Vicente-Serrano SM, López-Moreno JI (2008) Nonstationary influence of the North Atlantic Oscillation on European precipitation. J Geophys Res 113(D20120). doi:10.1029/2008JD010,382

Wanner H, Brönnimann S, Casty C, Gyalistras D, Luterbacher J, Schmutz C, Stephenson DB, Xoplaki E (2001) North Atlantic Oscillation-concepts and studies. Surv Geophys 22:321-382

Wibig J (1999) Precipitation in Europe in relation to circulation patterns at the $500 \mathrm{hPa}$ level. Int J Climatol 19(3):253-269

Wijngaard JB, Klein Tank AMG, Können GP (2003) Homogeneity of 20th century European daily temperature and precipitation series. Int J Climatol 23(6):679-692

Wild M, Ohmura A, Makowski K (2007) Impact of global dimming and brightening on global warming. Geophys Res Lett 34(L04702). doi:10.1029/2006GL028,031

Wilks DS (2006) Statistical methods in the atmospheric sciences, 2nd edn. Elsevier, Amsterdam

Zorita E, Kharin V, von Storch H (1992) The atmospheric circulation and sea surface temperature in the North Atlantic area in winter: their interaction and relevance for Iberian precipitation. J Clim 5(10): $1097-1108$

Zveryaev II (2004) Seasonality in precipitation variability over Europe. J Geophys Res 109(D05103). doi:10.1029/2003JD003,668

Zveryaev II (2006) Seasonally varying modes in long-term variability of European precipitation during the 20th century. J Geophys Res 111(D21116). doi:10.1029/2005JD006,821

Zveryaev II (2008) Interdecadal changes in the links between European precipitation and atmospheric circulation during boreal spring and fall. Tellus A 61(1): 50-56 